\title{
A Three Phase Based Four Switch Inverter for Renewable Energy Sources in Micro grid
}

\author{
Dawn S. Kurian" ${ }^{1}$ Tomson Thomas ${ }^{2}$, Anoopraj M. R ${ }^{3}$ \\ PG Scholar, Department of EEE, St. Joseph's College of Engineering \& Technology, Palai, India ${ }^{1}$ \\ Assistant Professor, Department of EEE , St. Joseph's College of Engineering \& Technology, Palai, India ${ }^{2,3}$
}

\begin{abstract}
Inverters designed using reduced active semiconductor devices can be of interest to the industry because of their lower cost and enhanced reliability linked to their less complex gating and control circuitries. In this paper a four switch three phase $b-4$ topology for the grid connected application in an effort to reduce the cost of the inverter is investigated. Admittedly, this topology warrants higher voltage ratings of the semiconductor devices used and the dc-link split capacitors used with respect to a conventional six-switch three-phase $b-6$ topology inverter for a specific set of grid voltages.

In this paper, application of four power semiconductor switch based three phase inverter has been proposed for renewable energy based generalized three phase micro grid interconnection. The b-4 of three phase inverter topology is investigated to make the commercial micro grid system to be cost effective and hardware optimized. A simple sinusoidal pulse width modulation (SPWM) is used to control the switching of the four switches. Main advantage of this converter is that it needs only four switches. As a result the system is less costly and also the complexity in associated with gating and control circuitry is very much reduced
\end{abstract}

Keywords: Four switch inverter, Sinusoidal pulse width modulation, Micro grid. VSI.

\section{INTRODUCTION}

Micro grid research has gained prime interest in the domain of power system research due to the reduced consumption of fossil fuel. Renewable energy is also penetrating into modern power grids to reduce the global carbon footprints. Three phase micro grids are receiving significant importance in the field of research due to the high level power transfer capability of the overall power network. Electrical grids tend to be more distributed, intelligent, and flexible. New power electronic equipment will dominate the electrical grid in the next decades.

In this paper a four switch based three phase inverter is proposed for grid connected applications. The number of power electronic switches needed for a conventional three phase inverter topology is six during the overall operation. To optimize the overall power circuit of the micro grid, a cost effective solution for the power circuit is to replace the traditional six switch based three phase inverter with a four switch based three phase inverter topology. The four-switch inverter, having a lower number of switches has been studied for the possibility of reducing the inverter cost. In comparison with conventional three phase inverter with six switches, the main features of this converter are the following:

1) Reduced number of switches and freewheeling diode

2) Low cost

3) Less complex gate driving circuitry

4) Reduction in conduction losses

\section{THREE PHASE FOUR SWITCH INVERTER}

A standard three phase voltage source inverter utilizes three legs with a pair of complementary power switches per phase. A reduced switch count voltage source inverter uses only two legs with four switches as shown in Fig. 1.

The circuit consists of 4 switches $S 1, S 3, S 4, S 6$, and two split capacitors $\mathrm{Cdc} 1$ and $\mathrm{Cdc} 2$.

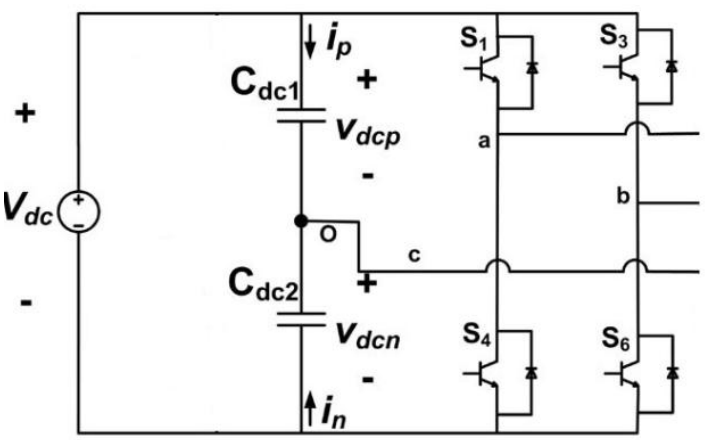

Fig. 1. Three Phase Four Switch Inverter

The dc voltage source Vdc is assumed to be formed by the renewable energy sources. The power circuit is the three phase four switch inverter. Two phases ' $a$ ' and ' $b$ ' are connected to the two legs of the inverter, while the third phase ' $c$ ' is connected to the center point of the dc link capacitors, $C d c 1$ and $C d c 2$. The 4 power switches are denoted by the binary variables, where the binary ' 1 ' corresponds to an ON state and the binary ' 0 ' corresponds to an OFF state. The states of the upper switches $(S 1, S 3)$ and lower switches $(S 4, S 6)$ of a leg are complementary that is $S 4=1-S 1$ and $S 6=1-S 3$. The terminal voltages Van, Vbn and Vcn of the inverter for RL load is can be expressed as a function of state of upper switches as follows,

$$
\begin{aligned}
& \mathrm{Van}=\frac{V c}{3}(4 \mathrm{~S} 3-2 \mathrm{~S} 1-1) \\
& \mathrm{Vbn}=\frac{\mathrm{Vc}}{3}(-2 \mathrm{~S} 3+4 \mathrm{~S} 1-1) \\
& \mathrm{Vcn}=\frac{\mathrm{Vc}}{3}(-2 \mathrm{~S} 3-2 \mathrm{~S} 1+2)
\end{aligned}
$$

Where $\mathrm{V} c$ is the voltage across the dc link capacitors Cdc1 and $\mathrm{Cdc} 2$. The above equations are the function of switching logic 
of the switches and the dc-link voltage. Where Van, Vbn, Vcn are inverter output voltages and $\mathrm{Vc}$ is the voltage across dc-link capacitors. S1 and S3 are the switching functions for each phase leg.

\section{III.POWER CIRCUIT CONFIGURATION OF THE PROPOSED THREE PHASE INVERTER}

Different distributed generators interface to the micro grid and the load using power electronic converters. The focus of this paper is on the three phase inverter interfacing the renewable energy sources to the micro grid.

The voltage source inverter not only operates in current control mode (CCVSI) to manage the harvested energy from the renewable energy sources to share the load active power $(P L)$ between power consumption from the local bus $(\mathrm{Pg})$ and the power supplied by inverter ( $P$ inv) but also the reactive power and harmonic power drawn by the load are also compensated by the CCVSI to ensure that the currents drawn from the local bus are sinusoidal and with unity displacement power factor (DPF). The utility grid neutral $N$ is electrically isolated from the dc-link midpoint of the VSI.

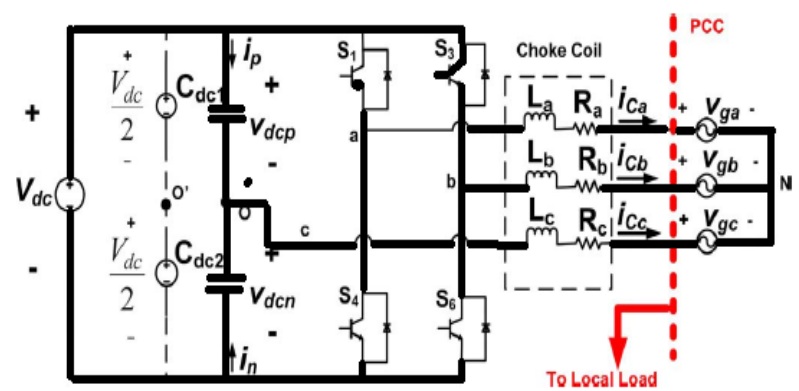

Fig. 2. Three Phase Four Switch Grid Connected Inverter

\section{EFFECT OF DC-LINK SPLIT CAPACITOR IMBALANCE IN GRID CONNECTED INVERTER}

Fig. 2 shows that the dc-link midpoint $\mathrm{O}$ is formed by splitting the dc link with two split capacitors $\mathrm{Cdc} 1$ and $\mathrm{Cdc} 2$. Ideally; the two capacitors must be of exactly same value to ensure perfect splitting of the dc-link voltage. However, in practical cases, the values are always different, even if it is made by the same manufacturer. Hence, the dc-link capacitors are charged; the splitting of $\mathrm{dc}$ voltage in the capacitors becomes asymmetrical. Mathematically, the initial dc value of the voltage of the lower capacitor $(V \mathrm{dcn})$ is $V 0$

$$
\mathrm{V} 0=\frac{C d c 1}{C d c 1+C d c 2} \mathrm{Vdc}
$$

As $C d c 1 \neq C d c 2, \mathrm{~V} 0 \neq \frac{V d c}{2}$ which will lead to a dc disturbance term $(V 0-(V \mathrm{dc} / 2)$. The dc disturbance terms tend to force a dc current in the circuit. This will cause an imbalance in the grid connected inverter.

Three phase four switch inverters have serially connected dc link capacitors and the center point of dc link is connected to one phase of three phase motors or loads. Among switching operation, there exists switching modes in which only one part (upper or lower part) of dc link capacitors is involving in power delivery, which causes voltage difference between the upper capacitor and that in the lower part of dc link capacitors. This voltage difference results in the discrepancy between the generated voltage and reference voltage in magnitude and angle. This difference in the generated voltage cause current ripples due to the unbalanced three phase voltage.

\section{CONTROL CIRCUIT}

Source impedance and center tap voltage fluctuation, originating from dc-link capacitors, are the two main reasons for causing unbalance in the phase current. Therefore, to restore the phase current from distortion and unbalance, compensations should be made at the time against both source impedance and center tap voltage fluctuation. Fig. 3 shows the control circuit of the three phase four switch inverter

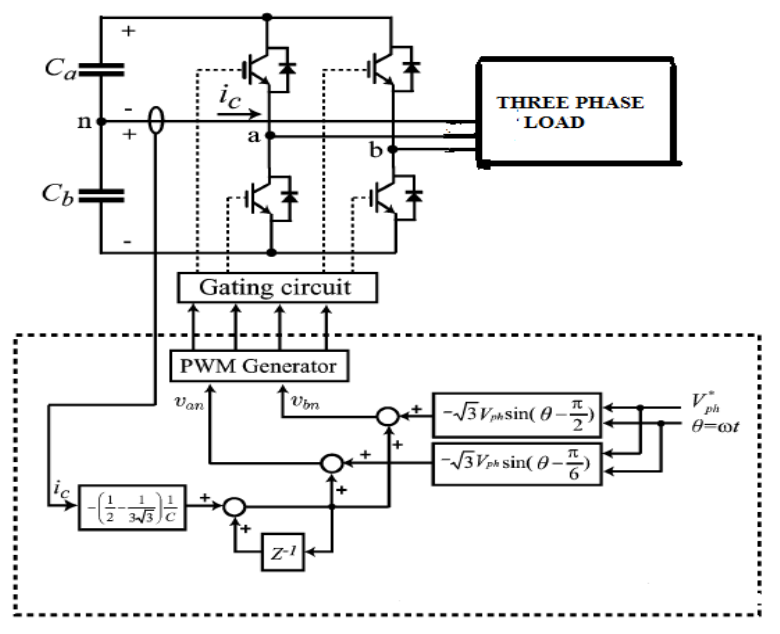

Fig. 3. Control Circuit of TPFSI

Equations (5) \& (6) give the overall phase current balancing equations.

$$
\begin{aligned}
& \mathrm{Vbn}=-\sqrt{3} V p h \sin \left(\omega t-\left(\frac{\pi}{2}\right)\right)-\frac{\left(\left(\frac{1}{2}-\frac{1}{3 \sqrt{3}}\right)\right) 1}{C} \int_{0}^{t} I c d t \\
& \mathrm{Van}=-\sqrt{3} V p h \sin \left(\omega t-\left(\frac{\pi}{6}\right)\right)-\frac{\left(\left(\frac{1}{2}-\frac{1}{3 \sqrt{3}}\right)\right) 1}{C} \int_{0}^{t} I c d t
\end{aligned}
$$

\section{SIMULATION RESULTS OF TPFSI}

Fig. 4 shows the complete simulink block diagram of the grid connected three phase four switch inverter system. Digital computer simulation model of four switch three phase inverter has been developed by using matlab simulink. The simulation work has been performed for the grid connected system. Four switch based three phase inverter fed system consists of a dc source, which is assumed to be formed from renewable energy sources, two split capacitors, and four switch three phase inverter. Fig. 4 shows the complete simulink block diagram of the system. This block diagram consists of 2 blocks. Switching pulses block generates the PWM pulses for 4 switches of FSTPI and grid connected FSTPI with local loads at the point of common coupling. 


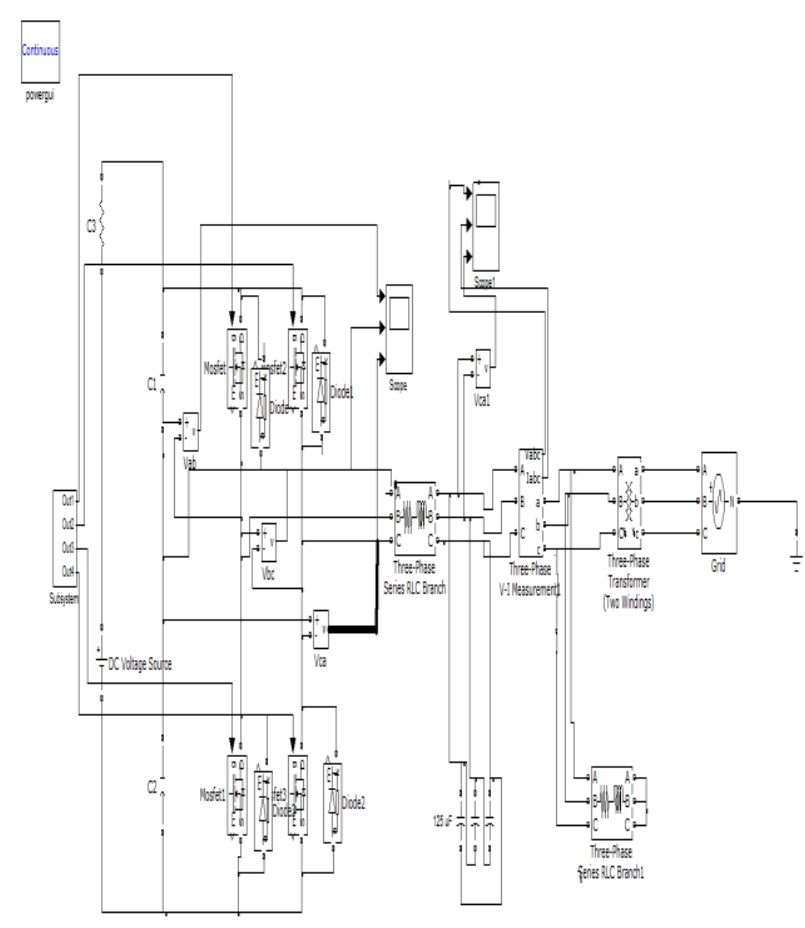

Fig. 4 Simulink Model of TPFSI

Fig. 4 shows the simulink model of three phase four switch inverter.

Fig. 5 shows the complete simulated output of inverter line voltages.
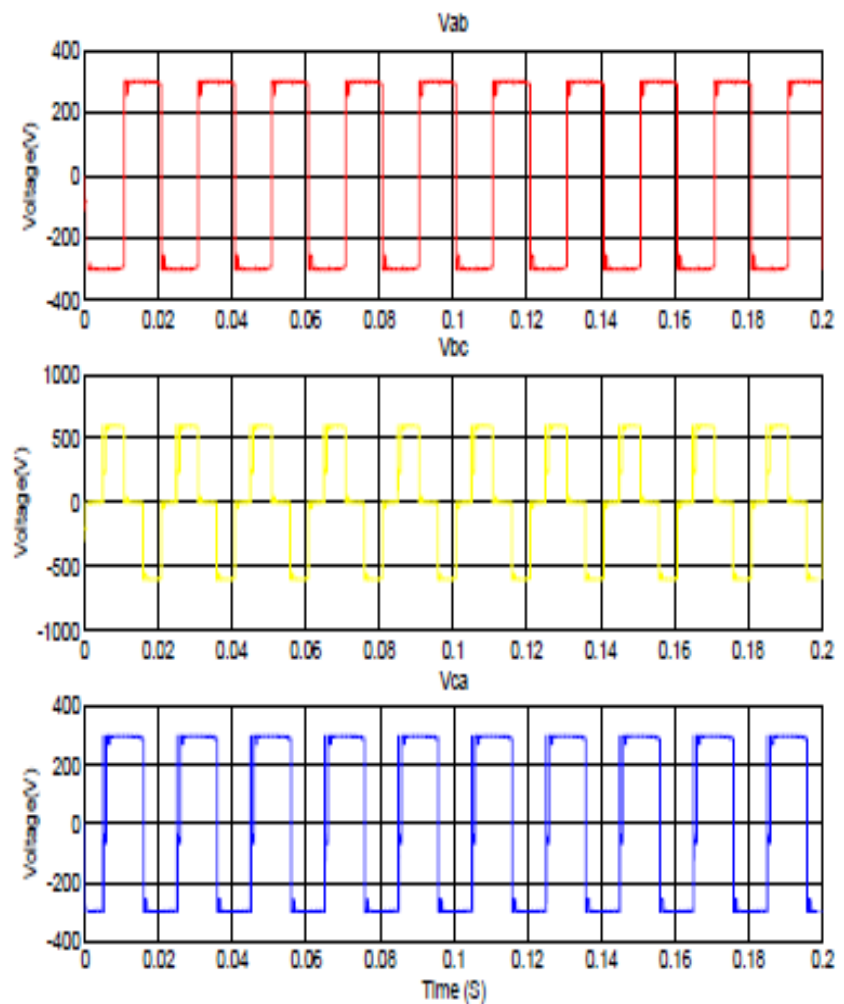

Fig. 5. Inverter Line Voltages
Fig. 6 shows the inverter phase voltages. From the simulation results it is verified that that the phase voltages are obtained as per the equations (1) - (3)
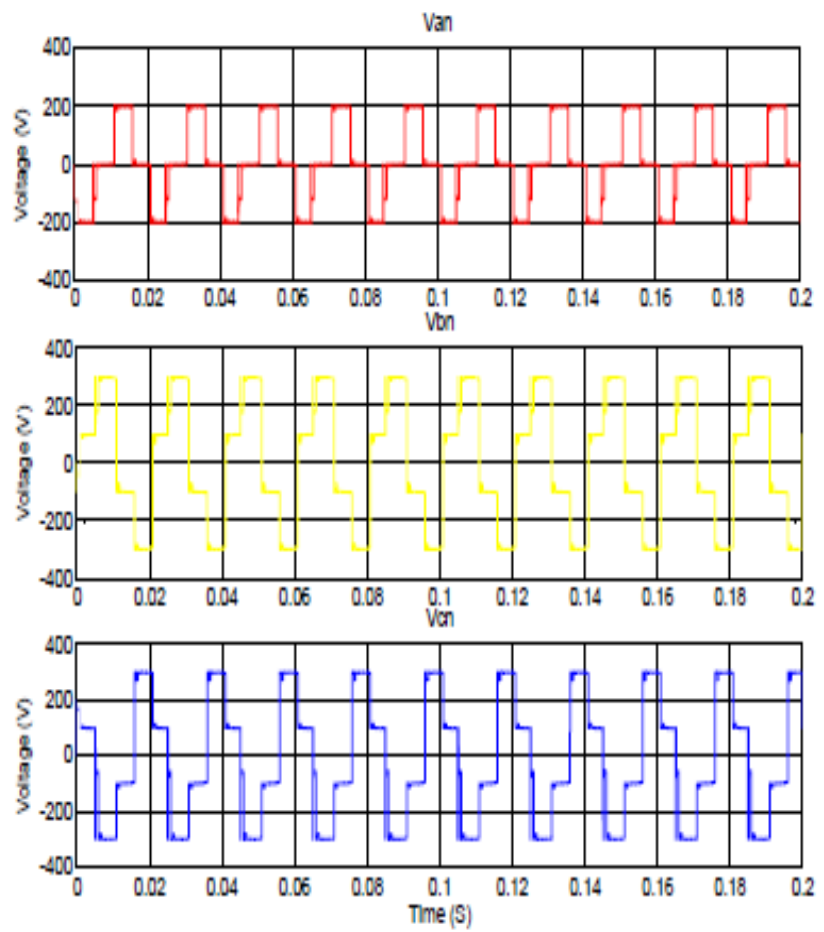

Fig. 6 Inverter phase voltage

Fig. 7 shows the current waveform. After applying current control scheme

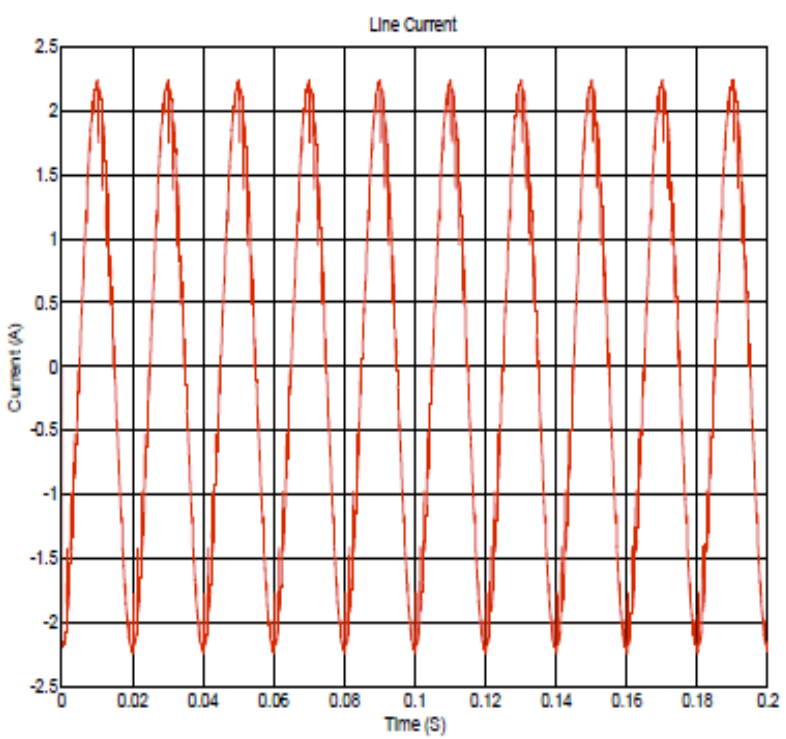

Fig. 7. Line Current

Fig. 7 shows the current waveform. After applying current control scheme the THD is very much reduced. Fig. 8 shows the THD analysis of the system. The results shows that the THD in line current is $7.69 \%$ which is within the accecptable limits. 

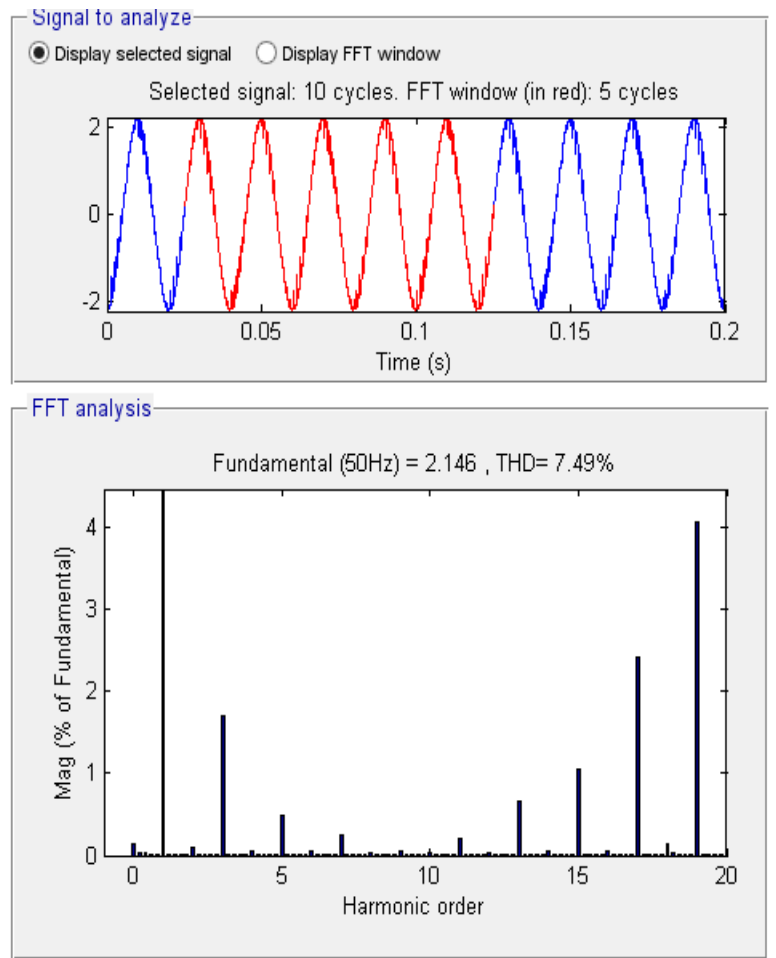

Fig. 8 THD of Line Current

\section{VII.CONCLUSION}

In this paper, application of four power semiconductor switch based three phase inverter (b-4 topology) has been proposed for renewable energy based generalized three phase micro grid interconnection. A simple SPWM is used to control the switching of the four switches. The current control of the inverter ensures proper active and reactive power flow from the grid along with grid current THD control in the presence of the nonlinear load at the grid. The simulation results are evaluated and verified. A three phase four switch inverter uses only four switches. It replaces the two switches with two capacitors and came as a cost effective solution for interfacing renewable sources and micro grid. The effectiveness of the proposed method was supported by the simulation and experimental results.

\section{REFERENCES}

[1] Y. Xue, J. Deng, and S. Ma, "Power flow control of a distributed generation unit in micro-grid," in Proc. IEEE Int. Power Electron. Motion Control Conf., 2009, pp. 2122-2125.

[2] J. Kim, J. Hong, and K. Nam, “A current distortion compensation scheme for four-switch inverters," IEEE Trans. Power Electron., vol. 24, no. 4, pp 1032-1040, Apr. 2009

[3] H. W. Van Der Broeck and J. D. Van Wyk, "A comparative investigation of a three-phase induction machine drive with a component minimized voltage-fed inverter under different control options," IEEE Trans. Ind. Appl., vol. IA-20,no. 2, pp. 309-320, Mar. 1984.

[4] S. Dasgupta, S. N. Mohan, Sanjib Kumar Sahoo, and Sanjib Kumar Panda, "Application of Four-Switch Based Three-Phase Grid-Connected Inverter to Con-nect Renewable Energy Source to a Generalized Unbalanced Microgrid System" IEEE Trans. on Ind. Electron.,Vol. 60, NO. 3, March 2013

[5] T. D. Nguyen, H. M. Nguyen, and H. H. Lee, \An adaptive carrier-based PWM for four-switch three-phase inverter," in Conf. Rec. ISIE, 2009, pp. 1552-1557. 